Canadian

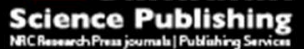

Canadian Journal of Civil Engineering Revue canadienne de génie civil

\title{
Estimation of Maximum Scour Depth near a Spur Dike
}

\begin{tabular}{|r|l|}
\hline Journal: & Canadian Journal of Civil Engineering \\
\hline Manuscript ID & cjce-2015-0280.R2 \\
\hline Manuscript Type: & Article \\
\hline Complete List of Authors: & $\begin{array}{l}\text { PANDEY, MANISH; Indian Institute of technology, Roorkee, CIVIL } \\
\text { ENGINEERING } \\
\text { Ahmad, Z.; Indian Institute of Technology, Roorkee, CIVIL ENGINEERING } \\
\text { Sharma, Pramod; Indian Institute of Technology, Roorkee, CIVIL } \\
\text { ENGINEERING }\end{array}$ \\
\hline Keyword: & $\begin{array}{l}\text { erosion and sediment < Hydrotechnical Eng., Spur dike, Clear-water scour, } \\
\text { Bank erosion, Maximum scour depth }\end{array}$ \\
\hline & \\
\hline
\end{tabular}




\title{
Estimation of Maximum Scour Depth near a Spur Dike
}

\author{
Manish Pandey $^{1} \quad$ Z. Ahmad ${ }^{2} \quad$ P. K. Sharma ${ }^{3}$ \\ ${ }^{1}$ Research scholar, IIT, ROORKEE-247667 INDIA \\ ${ }^{2}$ Professor, IIT, ROORKEE-247667, INDIA \\ ${ }^{3}$ Associate Professor, IIT, ROORKEE-247667, INDIA \\ Email: ${ }^{1}$ manishpandey3aug@gmail.com, ${ }^{2}$ zulfifce@gmail.com, ${ }^{3}$ drpksharma07@gmail.com
}

\begin{abstract}
Scour is a natural phenomenon in rivers caused by the erosive action of the flowing water on the bed and banks. Spur dikes are constructed across the flow to protect the bank erosion and facilitate the shifting of the river away from the bank. The spur dike undermines due to river-bed erosion and scouring, which is generally recognized as the main cause of spur dike failure. In this study, accuracy of existing equations for the computation of maximum scour depth has been checked with available data in the literature and data collected in the present study using graphical and statistical performance indices. Three new relationships are also proposed to estimate the maximum scour depth and maximum scour length upstream and downstream of spur dike. This new relationship for maximum scour depth is shown to perform better than other existing equations.
\end{abstract}

Key Words: Clear-water scour, spur dike, bank erosion and maximum scour depth.

\section{INTRODUCTION}

Spur dike is a man-made hydraulic structure used to divert or deflect the main water flow. Generally, spur dikes are fixed either perpendicular or at an angle to the flow direction in the channels. Scour is a main cause of failure of spur dikes and other hydraulic structures. Scour process involves the complexities of both the three-dimensional flow behaviour and the sediment transport. The general scour mechanism at spur dike is well understood after several studies, in which the horse shoe vortices and the wake vortices induced by the presence of the spur dike are responsible for the scour around the structure. The scour around abutments has been studied in greater detail than near spur dikes. In the past studies, it has been shown that the scour mechanism at spur dike is very similar to the scour mechanism at the abutment, in which spur dikes can be viewed as very thin rectangular vertical wall abutments (Melville, 1992). Therefore any reference made to abutments scour hereafter, also holds good for scour near spur dikes (Kothyari and Ranga Raju, 2001). The downstream flow and the principal vortex at the upstream corner of the spur dike, together with the wake vortices and secondary vortices at the middle part and the downstream corner of the spur dike, cause complex interactions between the bed materials and the fluid and are mainly responsible for the scour at spur dike. In addition to the vortex systems, other mechanisms may exist to cause local scour. In Fig. 1, the diverted down flow and the vortex system near an abutment and vertical wall spur dike are illustrated as per Kwan (1984). The estimation of the maximum depth of scour near spur dike is required for the safe and economical design of the spur dike. Depending on whether the approach flow carries sediment laden or clear water, scour around spur dikes is classified as: clear-water scour and live-bed scour. Clear-water scour occurs in the absence of sediment transport by approaching flow into the scour hole and live-bed scour develops when the scour hole is continuously fed 
with bed materials by the approaching flow. Nasrollahi et al. (2008) stated that scour depth increases with increase in the flow velocity and the maximum scour depth occurs at the initiation of sediment motion for clear water conditions. Various expressions and ideas have been derived by researchers to estimating the maximum scour depth around spur dikes for clear water condition.

The scour phenomenon near bridge abutments and spur dikes are considered the same (Melville, 1992). Therefore any reference made to abutment scour hereafter, also holds good for scour around spur dikes (Kothyari and Ranga Raju, 2001). Considerable similarities also exist between the flow patterns and scour processes at bridge abutments and spur dikes (Kothyary and Ranga Raju, 2001). The upstream face of the vertical wall abutment and spur dike also similar so we can say that developed equilibrium scour considerable similar for spur dike (perpendicular) as well as for vertical wall abutment. Large amount of abutment and spur dike scour literature represents, maximum scour always occurs at the upstream face of the vertical wall abutment and spur dike. Present study conducted for un-submerged spur dike and there is no need for submergence ratio.

Blockage ratio for spur dike and vertical wall abutment is $A_{b}=\frac{A_{s}}{y \cdot B}$, for un-submerged case $A_{s}=y \cdot l$.

Most of the previous studies on scour near spur dikes are concerned with prediction of maximum scour depth (Ahmad, 1953; Garde, 1961; Gill, 1972; Rajratnam and Nwachukwu, 1983; Froehlich, 1989; Melville, 1992\&1997; Nagy. 2004; and Dey and Barbhuiya, 2005). An integrated approach for determination of design equilibrium scour depth near abutments and spur dikes is presented by Dey and Barbhuiya (2005).

In this study, accuracy of existing equations (Frochlich, 1989; Lim, 1994; Husain et al., 1998; Nagy, 2004; and Dey and Barbhuiya, 2005;) is checked by present and previous experimental \& field data sets using graphical and statistical performances. A relationship for estimation of maximum scour depth near a spur dike is developed using the data of this study along with data available in the literature.

Fig. 1. Vortex system near an abutment or vertical wall spur dike (Kwan, 1984).

\section{Existing Equations of Scour Depth}

Numerous studies have been conducted on scour near a spur dike to predict the maximum scour depth. Most of these equations were based on laboratory experiments and field data. The scour depth depends upon various parameters such as: $F_{r}, F_{e}, d_{50}, \sigma, y, l, \mathrm{~V}, \mathrm{~V}_{\mathrm{c}}, S, \theta$ and $B$; where $F_{r}$ is Froude number based on approach velocity, $F_{e}$ is excess spur dike/abutment Froude number, $\mathrm{d}_{50}$ is median diameter of sediment, $\sigma$ is standard deviation $\left(\mathrm{d}_{84} / \mathrm{d}_{16}\right)^{0.5}$, y is approach flow depth, $l$ is transverse length of spur dike, $\mathrm{V}$ is average velocity of approach flow, $\mathrm{V}_{\mathrm{c}}$ is critical velocity of approach flow, $\mathrm{S}$ is relative density, $\theta$ represents the angle of spur dike in the direction of flow and $\mathrm{B}$ is the channel width. To compute the scour depth at equilibrium stage near a spur dike for different flow parameters and different river beds. Previous researchers viz; Dey and Barbhuiya (2005), Nagy (2004), Lim (1994), Froehlich (1989) and Husain et al (1998) have proposed different equations for non-cohesive sediments and these equations are given below: 
Froehlich (1989) proposed the following equation for scour near a spur dike using 164 published laboratory experimental data under clear water scour condition.

$$
\left(d_{s} / y\right)=\left(0.78 \cdot K_{1} \cdot K_{2} \cdot\left(L^{\prime} / y\right) \cdot\left(y / d_{50}\right) \cdot{ }^{0.43} \cdot F_{r}^{1.16} \cdot \sigma^{-1.87}+1\right)
$$

Where, $L^{\prime}=A_{e} / y ; A_{e}$ represents the flow area obstructed by the spur dike; $K_{1}$ correction factor equal to 1 for vertical wall abutment or spur dike; $K_{2}$ alignment correction factor $\left(\theta / 90^{\circ}\right)^{0.13}$.

Lim (1994) proposed an equation of scour depth using 252 data under clear water scour condition incorporating the effect of abutment shapes.

$$
\left(d_{s} / y\right)=0.9\left[\theta_{c}^{-0.375} F_{0}^{0.75}\left(d_{50} / y\right)^{0.25}\{0.99(l / y)+1\}\right]-2
$$

Where, $\mathrm{F}_{0}=$ Densimetric Froude number, $\mathrm{D} *$ is particle parameter $=\left[d_{50}(S-1) g / v^{2}\right]^{1 / 3}, \mathrm{~S}$ is relative density of sediment, $v$ is kinematic viscosity of fluid and $\theta_{c}$ is Shield's entrainment function, given by:

$$
\begin{array}{ll}
\theta_{c}=0.055 & D_{*}>150 \\
\theta_{c}=0.013 D_{*}^{0.29} & 20<D_{*} \leq 150 \\
\theta_{c}=0.04 D_{*}^{-0.61} & 10<D_{*} \leq 20 \\
\theta_{c}=0.14 D_{*}^{-0.64} & 4<D_{*} \leq 10 \\
\theta_{c}=0.24 D_{*}^{-1} & D_{*} \leq 4
\end{array}
$$

Equation (2) is derived for an abutment, aligned or perpendicular to the direction of approach flow, involves only the median size of non-cohesive sediment, approach flow velocity and transverse length of abutment. The results of Eq. (2) are comparable to the scour depths computed by Melville (1992) and Laursen (1963).

Husain et al. (1998) extended the approach of Laursen (1960) for estimate of scour near a spur dike. Laursen (1960) using a bridge model, proposed an enveloping curve for showing the effect of abutment encroachment on scour depth. They stated that the ratio of scour depth $\left(d_{s} / y\right)$ increases with the increase of the non-dimensional encroachment width - depth ratio $(b / y)$ and contraction ratio $\alpha=(B-b) / B$. Their experimental results were in good agreement with Laursen's (1960) finding. Husain et al. (1998) concluded that scour depth is significantly affected by dimension of abutment as well by encroachment width-depth ratio.

$$
\left(d_{s} / y\right)=K\left(S_{f}\right)^{A_{1}} F_{r}{ }^{A_{2}}\left(d_{50} / y\right)^{A_{3}}(B / y)^{A_{4}}\left[1-\left(\frac{B-b}{B}\right)\right]^{A_{5}}
$$

In this equation $K, \mathrm{~A}_{1}, \mathrm{~A}_{2}, \mathrm{~A}_{3}, \mathrm{~A}_{4}$ and $\mathrm{A}_{5}$ are constants. The value of $\mathrm{K}$ and $\mathrm{A}_{1}$ through $\mathrm{A}_{5}$ are $4.5,1.0,0.653,0.225,0.598$ and 1.80 for uniformity of sediment sizes. $b$ is encroached width which is equal to $l$ for vertical wall rectangular abutment. Safe factor, $S_{f}$ is 2.2, 1.0 and 1.77 for rectangular, circular-edge and trapezoidal abutments, respectively.

Nagy (2004) proposed an equation for computing maximum scour depth around bridge abutment using 193 experimental data sets. The spur dike length ratio $(l / y)$ had significant effect compared to intrusion ratio $(l / B)$.

$$
\left(d_{s} / y\right)=3 \cdot \frac{(l / y)^{0.42}(\sin \theta)^{0.717}}{\left(d_{50} / y\right)^{0.277}} \cdot F_{r}^{2}
$$


Dey and Barbhuiya (2005) proposed equations to predicting scour depth for different shapes of abutments as given in Eqs. 5 (a-c). Dey and Barbhuiya (2005) used both uniform and nonuniform sediment for their study. They used vertical wall abutments, $45^{\circ}$ wing-wall abutments and semicircular abutments. They conducted 99 number of experiments for each case of abutment for uniform sediment and 27 number of experiments for each case of abutment for nonuniform sediment. For equilibrium scour condition Dey and Barbhuiya (2005) also stated that the characteristic parameters affecting the equilibrium scour depth are excess abutment Froude number, flow depth $\&$ abutment length ratio and abutment length $\&$ sediment ratio.

$$
\begin{aligned}
& d^{\prime}{ }_{s}=7.281 F_{e}^{0.314} y^{0.128} l^{\prime-0.167} \quad \text { (For vertical wall) } \\
& d^{\prime}{ }_{s}=8.319 F_{e}^{0.312} y^{0.101} l^{-0.231} \quad \text { (For } 45^{\circ} \text { wing-wall) } \\
& d^{\prime}{ }_{s}=8.689 F_{e}^{0.192} y^{\prime 0.103} l^{-0.296} \quad \text { (For semicircular) }
\end{aligned}
$$

In this equation, $d_{s}^{\prime}=d_{s} l l, \mathrm{~F}_{\mathrm{e}}=$ excess abutments Froude number $=\frac{\left(V-\xi V_{c}\right)}{\sqrt{(s-1) g l}}, y^{\prime}=y / l$ and $l^{\prime}=l / d_{50}$ and $\xi$ is shape coefficient equal to 0.5 for vertical wall abutments and spur dikes. The scour near an abutment takes place, when $\left(\mathrm{V}-\xi \mathrm{V}_{\mathrm{c}}\right)$ i.e. $\mathrm{V}_{\mathrm{e}}$ is greater than zero.

\subsection{Data Description}

Both laboratory experimental data and field data for clear water scour near a spur dike and abutment were collected from several studies available in literature for use in the present study. There were 162 laboratory experimental data and 6 field data taken by several previous studies. In addition, 15 experimental data were collected in the present study. These 183 data sets were used for checking the accuracy of existing equations in the present. Flow and sediment property of experimental and field data are shown in Table 1.

Lim (1997) conducted laboratory experiments on a $0.25 \mathrm{~m}$ thick sand bed having 0.94 $\mathrm{mm}$ median diameter and standard deviation as 1.25 . Five abutment models $(50 \mathrm{~mm}, 75 \mathrm{~mm}, 100$ $\mathrm{mm}, 125 \mathrm{~mm}$ and $150 \mathrm{~mm}$ ) were used by Lim for his study. All the tests were conducted for clear water condition. Lim (1997) conducted 11 numbers of experiments for development of the maximum scour depth monitored until an equilibrium condition of scour was reached, and time required to reach this condition was about 3 to 8 days. Lim analyzed this data from one of the best scour abutments data which was provided by The University of Auckland. Most of the Auckland University experiments were conducted for long time up-to 10 days or more. Data sets of 252 laboratory experiments were conducted under clear water scour. The range of the parameters is $1.18 \leq \mathrm{Fr} \leq 4.32,0.22 \leq l / y \leq 19.6,0.001 \leq d_{50} / y \leq 0.058$ and $1.17 \leq \sigma \leq 4.11$.

Husain et al. (1998) conducted a series laboratory experiments in a $15 \mathrm{~m}$ long, $1.37 \mathrm{~m}$ wide and $0.62 \mathrm{~m}$ deep rectangular flume having $0.275 \mathrm{~m}$ thick sand bed, $0.775 \mathrm{~mm}$ median diameter and standard deviation as 1.29. Three shapes of abutments i.e. rectangular, circular edge and trapezoidal were used by Husain et al. (1998). Equilibrium condition of scour reached within 12 hours. A constant mean approach of flow depth of $0.22 \mathrm{~m}$ was set for all. They computed critical shear velocity $(\mathrm{V} * \mathrm{c})$ by shields method and critical velocity $\left(\mathrm{V}_{\mathrm{c}}\right)$ computed by equation of Lauchlan and Melville (2001), as given in Eq. 6.

Dey and Barbhuiya (2005) carried out experiments in a flume of $20 \mathrm{~m}$ long $0.9 \mathrm{~m}$ wide and $0.7 \mathrm{~m}$ deep over sand and gravel beds. They conducted experiments for both uniform and non-uniform sediment. In this study, uniformity of sediment was defined by Dey et al. 1995, 
which is less than 1.4 for uniform sediments. They also used Shields method for computing critical shear velocity and critical velocity calculated by equation of Lauchlan and Melville (2001). In conducted experiments by them for clear water scour condition, the equilibrium condition was reached within 48-50 hours. They introduced a term excess abutment/spur dike Froude number.

Nasrollahi et al. (2008) conducted their experiments in a $12 \mathrm{~m}$ long, $2 \mathrm{~m}$ wide and $0.6 \mathrm{~m}$ deep horizontal flume over $0.45 \mathrm{~m}$ thick non-cohesive uniform sediment bed having $1.3 \mathrm{~mm}$ median diameter and standard deviation as 1.3. Both types of spur dikes, permeable and impermeable were having transverse length as $0.25,0.375,0.5,0.625$ and $0.75 \mathrm{~m}$, were used. A constant discharge of $0.08 \mathrm{~m}^{3} / \mathrm{s}$ was used. Equilibrium condition of scour was reached within 24 hours for impermeable spur dikes and 12 hours for permeable spur dikes.

Coleman et al. (2003) conducted experiments in number of different flumes at The University of Auckland. Uniform sediments were used in each flume having $0.8 \mathrm{~mm}$ to $1.02 \mathrm{~mm}$ as median diameter. Relative flow velocities $\left(\mathrm{V} / \mathrm{V}_{\mathrm{c}}\right)$ were varied from $0.46-0.99$ and ratio of $y / l$ was varied from 0.17 - 4.0. Scoured bed level and scour depth were measured by using an Ultrasonic Depth-Sounder with accuracy of $\pm 0.4 \mathrm{~mm}$. They also used 6 field experimental data for their research work. Some additional data were used in that research which were measured at The University of Auckland by Tey (1984), Kwan (1984) and Dongol (1994). These three researchers study measured the development of local scour near abutment for flows approaching threshold conditions $\left(\mathrm{V} / \mathrm{V}_{\mathrm{c}}=0.87-0.99\right)$. Tey (1984) and Kwan (1984) used short abutments, while Dongol (1994) used both short and long abutments. Short and long abutments are defined by ratio of $y / l$. Short abutments were observed to have $y / l>1$ while long abutments were observed to have $y / l \leq 1$.

\section{EXPERIMENTAL WORK}

All experimental work was carried out in the Hydraulic Engineering laboratory of Civil Engineering Department, Indian Institute of Technology Roorkee, India. All experiments were conducted under clear-water scour condition in a $24 \mathrm{~m}$ long, $1.0 \mathrm{~m}$ wide and $0.50 \mathrm{~m}$ deep fixed bed flume. The longitudinal slope of the flume was 0.0005 . A working section of size $4 \mathrm{~m} \times 1 \mathrm{~m}$ $\times 0.6 \mathrm{~m}$ (length $\mathrm{x}$ width $\mathrm{x}$ depth) was prepared for the all experiments. The working section of the flume was $13.7 \mathrm{~m}$ downstream to the flume entrance. Working section of flume was fully filled by fine sand having $0.27 \mathrm{~mm}$ median diameter $\left(\mathrm{d}_{50}\right)$ of sediment, standard deviation of 1.23 and relative density as 2.65 . A rectangular plate having $2 \mathrm{~mm}$ thickness and different transverse length i.e. $6 \mathrm{~cm}, 8.5 \mathrm{~cm}, 10 \mathrm{~cm}, 12 \mathrm{~cm}$ and $20 \mathrm{~cm}$ was used as the impermeable spur dike. Spur dike, which was located at the $15.7 \mathrm{~m}$ away from the flume entrance. For each spur dike, three experiments were conducted for three different discharges i.e. $0.0159,0.0189$ and $0.021 \mathrm{~m}^{3} / \mathrm{s}$, which were having velocities as $0.159,0.189$ and $0.21 \mathrm{~m} / \mathrm{s}$, respectively. Critical velocity for sediment was $0.252 \mathrm{~m} / \mathrm{sec}$ and ratio of $\mathrm{V} / \mathrm{V}_{\mathrm{c}}$ shown in Table 2. Discharge was measured by using sharp crested weir which was located at the end section of the flume. Present study were conducted for 18 hours. But for all runs, it was observed that equilibrium scour reach within 10 hours. After equilibrium condition i.e. 10 hour for present study, scour depth remain same at 1118 hour (every 30 minute interval). After equilibrium scour condition, scour depths were measured by point gauge with $\pm 0.1 \mathrm{~cm}$ accuracy. Before the start of each experimental run the spur dike was fixed at left side of flume wall and perpendicular across the water flow. Working section of flume was made perfectly level with respect to the longitudinal slope of flume and then covered with $3 \mathrm{~mm}$ Perspex sheet. Then the predetermine flow condition was established 
using the inlet valve and the tail gate, the Perspex sheet was removed very carefully so that no scour developed near the spur dike due to this. Essentially these experimental runs were carried out to check other's experimental data, and hence, 15 runs were conducted. Experimental data have been shown in Table 3, with maximum scour depth at equilibrium stage. Assuming $d_{s}$ as maximum scour depth near spur dike, thus, all experiments were conducted under clear water scour conditions i.e. $\left(\mathrm{V} / \mathrm{V}_{\mathrm{c}}\right)<1$. $\mathrm{V}$ is approaching mean velocity and $\mathrm{V}_{\mathrm{c}}$ is critical shear velocity for sediment, $\mathrm{V}_{\mathrm{c}}$ is defined by Lauchlan and Melville (2001) equation, as follows.

$$
\frac{V_{C}}{V_{*_{C}}}=5.75 \log \left(\frac{y}{k_{s}}\right)+6
$$

Where y is approach flow depth, $\mathrm{k}_{\mathrm{s}}$ is equivalent roughness height which is equal to $2 \mathrm{~d}_{50} . \mathrm{V} *_{\mathrm{c}}$ was calculated by Shields method.

Fig. 2. Photometric view of experimental setup.

\section{RESULTS AND ANALYSIS}

\subsection{Accuracy of Existing Equations for Scour Depth}

Various expressions have been proposed by previous investigators (Garde, 1961; Gill, 1972; Frochlich, 1989; Lim, 1994 \& 1997; Melville, 1992 \& 1997; Husain et al., 1998; Nagy, 2004; and Dey and Barbhuiya, 2005) for estimating the maximum scour depth near spur dikes. However, equations proposed by (Frochlich, 1989; Lim, 1994; Husain et al., 1998; Nagy, 2004; and Dey and Barbhuiya, 2005) are commonly being used there for in this present study. It is indented to check the accuracy of these equations using collected data in the present study and those data available in the literature and accuracy of these equations was checked by minimum percentage of error i.e. $\pm 25 \%$ and statistical performances. Fig. 3 (a-e) shows the percentage mean error between observed and computed scour depths. Fig. 3 (a) shows the agreement between observed and computed data by the expression of Froehlich (1989), around 53\% of the data sets were found to be within the $\pm 25 \%$ error line while for Nagy (2004) it was $41 \%$ only. Nagy (2004) neglects the effect of shape factor. Neglecting the effect of shape factor, affects the accuracy of results, especially for the data of Coleman et al. (2004), which have large size of spur dikes. In Fig. 3 (c), the data plot shows that the equation of Husain et al. (1998) gives underestimated values for all points except of their data located within the $\pm 25 \%$ error lines, very less data points are located within $\pm 25 \%$ error line. In fact, only their data points fit their expression because they conducted experiments for rectangular, trapezoidal and circular edge models for a very short time period, as shown in Fig. 3 (c). Even Husain et al. (1998) added several coefficients to represent many variables in their integrated expression. In Fig. 3 (e) the data plot shows that the equation of Dey and Barbhuiya (2005) gave $80 \%$ data points within $\pm 25 \%$ error line while Lim (1994) gave $57 \%$ of the data points. Dey and Barbhuiya (2005) introduced a term excess abutment Froude number for vertical, $45^{\circ}$ wing wall and semicircular abutments but Lim (1994) used densimetric Froude number. Densimetric Froude number, effects on the accuracy of results, especially for the data of Dey and Barbhuiya (2005).It is concluded herein from the above graphical discussion that the results obtained from Dey and Barbhuiya (2005) in Fig. 3 (e) shows better agreements. Equation of Dey and Barbhuiya (2005) i.e. Eq. (5), 
has a wide range of application since it has several effective parameters. The scatter of some data points may refer to the variation of experimental time for each researcher. For computing maximum scour depth near abutment, equation proposed by. Dey and Barbhuiya (2005) is more accurate as compared to the others but Dey and Barbhuya (2005) used only their experimental data for predicting the scour depth near abutments, so there were number of outliers from the $\pm 25 \%$ error line. In previous studies, it is stated that the values of Froude number/excess Froude number/densimetric Froude number have significant effect. The other parameters i.e. flow depth - spur dike length ratio and spur dike length - sediment ratio have been shown to be secondary importance.

Fig. 3 (a). Comparison between computed and observed dimensionless scour depths using Frochlich (1989) with observed values.

Fig. 3 (b). Comparison between computed and observed dimensionless scour depths using Lim (1994) with observed values.

Fig. 3 (c). Comparison between computed and observed dimensionless scour depths using Husain et al. (1998) with observed values.

Fig. 3 (d). Comparison between computed and observed dimensionless scour depths using Nagy (2004) with observed values.

Fig. 3 (e). Comparison between computed and observed dimensionless scour depths using Dey and Barbhuiya (2005) between observed and computed scour depth.

\subsection{A New Relationship for Scour Depth and maximum Scour Length}

Analytical and experimental analyses are described to predict the maximum scour depth near spur dike at equilibrium stage. Dey and Barbhuiya (2005) have proposed a good relationship for scour depth but they used only their data for deriving relationship. This equation need to be analysed with data from other investigators for wider applicability. Relationship proposed by Dey and Barbhuiya (2005) represents only $80 \%$ data within $25 \%$ error line when data from other publications were used. Therefore, it can be said that relationship proposed by Dey and Barbhuiya (2005) needs some modification to increase its accuracy. For estimating a new scour depth relationship, a regression analysis was done including more data from previous publications. Eq. (7) was derived for calculating the maximum scour depth near spur dike. The results of regression analysis presented a mounting evidence that the excess abutment Froude number, $F_{e}$, has significant effect rather than the abutment Froude number, $F_{z}$. The Eq. (7) gives the best result for predicting the maximum scour depth near a spur dike. Fig. 4 shows the line of perfect agreement between observed and computed maximum scour depth for the 183 datasets which were used in predicting the formula. Almost $90 \%$ of the data points are within $\pm 25 \%$ error lines, as shown in Fig. 5. The resulting values for the proposed relationship give much better 
agreement with observed data. The regression coefficient $\left(\mathrm{R}^{2}\right)$ of proposed equation is 0.91 , which is better than $\mathrm{R}^{2}$ for Dey and Barbhuiya (2005) which was 0.89 .

$$
\left(d_{s e} / l\right)=5.686 F_{z}^{0.276} y^{\prime 0.248} l^{\prime-0.163}
$$

Fig. 4. Comparison between computed and observed dimensionless scour depths using present equation with observed values

Figure 5 Comparison between equation of Dey and Barbhuiya (2005) and present equation.

Figure 6 Scour depth contours and scour hole at equilibrium stage.

Where, $F_{z}=\frac{\left(V-\xi V_{C}\right)}{\sqrt{g l}}, \xi=0.5$ for vertical wall abutment and vertical spur dike. Graphical representation of present equation was given below in Fig. 4. For limitation of $F_{z}, V / V_{c}$ should lie between $0.5-1$.

In present study, two more equations also proposed for computing maximum scour hole length upstream and downstream the spur dike at equilibrium stage, as follows Eq. 1\&2. For estimating these relationships, a regression analysis was done including present and data used by Ezzeldin et al. (2007). The regression coefficient $\left(\mathrm{R}^{2}\right)$ of proposed equations are 0.93 and 0.85 , respectively Eq. 7 (a) \& 7 (b). Figure 7 (a) \& 7 (b) shows the line of perfect agreement between observed and computed maximum scour length for the present and data used by Ezzeldin et al. (2007).

$$
L_{u / s}=0.35 F_{z}^{0.22} y^{10.96} l^{10.41}
$$

Equation for maximum scour hole length downstream the spur dike;

$$
L_{d / s}=4.07 F_{z}^{0.46} y^{10.09} l^{0.17}
$$

\subsection{Statistical Performance of Equations}

The accuracy of selected relationships was also checked by using the statistical performance indices. These statistical parameters were used to measure the extent of the agreement between the observed and predicted maximum scour depths. If $\mathrm{Y}$ is the observed value and $\mathrm{Y}^{\prime}$ is the corresponding predicted value, the different performance indices may be defined (Maier and Dandy, 1996; Rajurkar et al., 2004; and Riahi-Madvar et al. 2009):

Coefficient of correlation,

$$
C C=\frac{N \Sigma Y Y^{\prime}-\Sigma Y \Sigma Y^{\prime}}{\sqrt{N \Sigma Y^{2}-(\Sigma Y)^{2} \sqrt{N \Sigma Y^{\prime 2}-\left(\Sigma Y^{\prime}\right)^{2}}}}
$$


Mean absolute error,

$$
M A E=\frac{1}{N} \sum_{i=1}^{N}\left|Y_{i}-Y^{\prime}{ }_{i}\right|
$$

Mean square error,

$$
M S E=\frac{1}{N} \sum_{i=1}^{N}\left(Y_{i}-Y_{i}^{\prime}\right)^{2}
$$

Mean root square error,

$$
M R S E=\sqrt{\frac{\sum_{i=1}^{N}\left(Y_{i}-Y_{i}^{\prime}\right)^{2}}{N}}
$$

Mean absolute percentage error,

$$
M A P E=\frac{100}{N} \sum_{i=1}^{N} \frac{\left|Y_{i}-Y_{i}^{\prime}\right|}{\left|Y_{i}\right|}
$$

In Eqs. (8-12), $\mathrm{N}$ is the number of datasets $(\mathrm{N}=183$ for present study). The values of coefficient of correlation (CC), mean absolute error (MAE), mean squared error (MSE), mean root square error (MRSE) and mean absolute percentage error (MAPE) are listed in Table 4. The CC of present relationship i.e. Eq. 7, is highest than among all relationships, and MAE, MSE, MRSE and MAPE are lowest. Statistical performances indicate that the relationship proposed by Dey and Barbhuiya (2005) is better than other previous relationships. However, it was observed that the present relationship gives far better results than among all, as follows Fig. 4, Fig. 5 and Table 4.

\subsection{Location of Maximum Scour Depth and Its Pattern}

Maximum scour depth is an important factor for dimensionless analysis and predicting the maximum scour depth relationships. Maximum scour depths typically occurs at the junction between the spur dike wall and channel. It was observed that the maximum scour depth occurs upstream, nose of spur dike due to high bed shear stress, similar as Garde (1961), Melville (1992) and Vaghegi et al. (2009). Depth of scour is relatively more just upstream side of spur dike as compared to the downstream side. Scour hole was spread up to a width of $3 l$ from the wall junction of the channel and depends on transverse length and flow velocity. Zone of influence of spur dike i.e. extend of scour hole is lesser above the upstream side as compared to the downstream side. However the volume of scour hole is much greater (up to $65 \%$ of total volume) on the upstream side as compared to that on the downstream side. Small dunes having maximum height not greater than $50 \%$ of maximum scour depth were observed by on the downstream side of spur dike. Scour depth contours and 3D view of scour-hole shows the location of maximum scour depth and scour depth variation, as follows in Fig. 6. 3D view of scour hole at equilibrium stage shows scour depth variation with deferent colors, such as green for maximum scour region and blue for deposited sediment. 
Figure 7 (a) Comparison between computed and observed dimensionless scour length upstream the spur dike

Figure 7 (b) Comparison between computed and observed dimensionless scour length downstream the spur dike.

\section{CONCLUSIONS}

Maximum scour depth equations proposed by five researchers (Dey and Barbhuiya, 2005; Nagy, 2004; Froehlich, 1989; and Lim, 1994) were used for checking the accuracy of scour depth at equilibrium stage, graphically and statistically, as follows in Fig. 3 (a-e) and Table 4. It was observed experimentally that the values of the spur dike's Froude number have significant effect on the equilibrium scour depth. The other parameters have got secondary importance on the equilibrium scour depth. A new relationship is proposed for estimating maximum scour depth, as follows, Eq. (7) and this relationship predicts the maximum scour depth at equilibrium stage with reasonable accuracy. This relationship was checked graphically and statistically, and the resulting values for the derived relationship gave much better agreement with observed data than other previous relationships, as follows in Fig. 4, Fig. 5 and Table 4. For location of maximum scour depth, the aforementioned diagram i.e. Fig. 6 clearly states that a spur dike can produce significant changes in the distribution of scour depths at equilibrium stage. It was observed that the maximum scour depth always occurs at upstream side, nose of spur dike and erosive sediment deposited at downstream side. The following conclusions were obtained:

1) It was observed that the relationship proposed by Dey and Barbhuiya (2005) gives better agreements with observed data than other previous relationships.

2) The present relationship performs much better in prediction of maximum scour depth.

3) It was observed that the maximum scour depth occurs at upstream side, near nose of spur dike and erosive sediment was deposited at downstream side.

\section{References}

Ahmad, M. 1953. Experiments on design and behavior of spur dikes. In Proceeding of the conference on International Hydraulic Convention, ASCE, New York, pp. 145-159.

Baba, Y., Camenen, B., Peltier, P., Thollet, F., and Zhang, H. 2010. Flow and bed load dynamics around spur dyke in a compound channel. In Proceeding of the conference on 11 th International Symposium on River Sedimentation (ISRS), Stellenbosch, pp. 1-11.

Coleman, S.E., Lauchlan, C.S., and Melville, B.W. 2003. Clear-water scour development at bridge abutments. Journal of Hydraulic Research, ASCE, 41: 521-531.

Cui, Z., and Zhang, X., 1978. Flow and sediment simulation around spur dike with free surface using 3-d turbulent model. In Proceeding of the conference on Global Chinese Scholars on Hydrodynamics, 241-249.

Dey, S., Bose, S. K., and Sastry, G.L.N. 1995. Clear water scour at circular piers: A model. Journal of Hydraulic Engineering, ASCE, 121(12), 869-876. 
Dey, S., and Barbhuiya, A. K. 2005. Time variation of scour at abutments. Journal of Hydraulic Engineering, ASCE, 131(1): 11-23.

Dongol, D.M.S. 1994. Local Scour at Bridge Abutments. School of Engineering, Report No. 544, The University of Auckland, Auckland, New Zealand.

Froehlich, D.C. 1989. Local scour at bridge abutments. In Proceeding of the national conference on Hydraulic Engineering, New Orleans, ASCE, Louisiana, pp. 13-18.

Garde, R.J., Subramanya, K., and Nambudripad, K.D. 1961. Study of scour around spur-dikes. Journal of Hydraulic Engineering, ASCE, 87(6): 23-27.

Gill, M.A. 1972. Erosion of sand beds around spur-dikes. Journal of Hydraulic Engineering, ASCE, 98(9):1587-1602.

Husain, D., Quaraishi, A. A., and Ibrahim, A. 1998. Local scour at bridge abutments. JKAU: Eng. Sci. 10:141-153.

Kothyari, U.C., and Ranga Raju K.G. 2001. Scour around spur-dikes and bridge abutments. Journal of Hydraulic Research, ASCE, 39: 367-374.

Kwan, T.F. 1984. Study of Abutment Scour. School of Engineering, Report No. 328, The University of Auckland, Auckland, New Zealand.

Laursen, E.M. and Toch, A. 1953. A generalized model studied of scour around bridge piers and abutments. Minnesota International Hydraulics, Report No. 120 ConventionState university of IOWA USA.

Laursen, E.M., and Toch, A. 1960. Scour at bridge crossing. Journal of the Hydraulics Division, ASCE, 86(2):39-54.

Laursen, E. M., 1963. Analysis of relief bridge scour. Journal of Hydraulic Engineering, ASCE. 89(3): 93-118.

Lauchlan, C.S., and Melville, B.W. 2001. Riprap protection at bridge piers. Journal of Hydraulic Engineering, ASCE, 127: 412-418.

Lim, S.Y. 1994. Equilibrium clear-water scour around an abutment. Journal of Hydraulic Engineering, ASCE, 123: 237-243.

Lim, S.Y., and Cheng, N.S. 1997. Prediction of live-bed scour at bridge abutments. Journal of Hydraulic Engineering, ASCE, 124: 635-638.

Maier, H. R., and Dandy, G. G. 1996. The use of artificial neural networks for the prediction of water quality parameters. Water Resources Research, 32(4): 1013-1022.

Marson, C., Fiorotto, V., and Caroni. E. 2006, Clear water scour analysis around groins and bridge abutments. . In Proceeding of the conference on Hydraulic symposium, London, pp: 1749-1775. 
Melville, B.W. 1992. Local scour at bridge abutments. Journal of Hydraulic Engineering, ASCE, 118: 615-631.

Melville, B. W. 1997. Pier and abutment scour: integrated approach. Journal of Hydraulic Engineering, ASCE, 123: 125-136.

Molinas, A., Kheireldin, K., and Wu, B. 1998. Shear stress around vertical wall abutments. Journal of Hydraulic Engineering, ASCE, 124: 822-830.

Nasrollahi, A., Ghodsian, M., and Neyshabouri, S.S.A.S. 2008. Local scour at permeable spur dikes, Journal of Applied Sciences. 3398-3406.

Nagy, H.M. 2004. Maximum depth of local scour near emerged vertical wall spur dike. Alexandria Engineering Journal. 43: 819-830.

Rajurkar, M. P, Rajurkar, M.P., Kothyari, U.C., and Chaube, U.C. 2004. Modelling of the daily rainfall-runoff relationship with artificial neural network. Journal of Hydrology, 285: 96-113.

Riahi-Madvar, H., Ayyoubzadeh, S., Khadangi, E., and Ebadzadeh, M. 2009. An expert system for predicting longitudinal dispersion coefficient in natural streams by using ANFIS. Expert Systems with Applications, 36: 8589-8596.

Talaat, A., Attia, K., Elsaeed, G., and Ibraheem, M. 2009. Implementation of spur dikes to reduce bank erosion of temporary diversion channels during barrages construction. Australian Journal of Basic and Applied Sciences, 3(4): 3190-3205.

Tey, C.B. 1984. Local Scour at Bridge Abutments. School of Engineering, Report No. 329, The University of Auckland, Auckland, New Zealand.

Vaghefi, M., Ghodsain, M., and Nayshaboori, S.A.A.S. 2009. Study on the effect of a T-shaped spur dike length on scour in a $90^{\circ}$ channel bend. The Arabian Journal for Science and Engineering, 34(2B): 337-348.

Zhang, H., and H. Nakagawa 2008. Scour around spur dyke: recent advances and future researches. Annuals of the Disaster Prevention Research Institute, Kyoto Uni. 51: 633-652 
Table 1 Range of data

\begin{tabular}{|c|c|c|c|c|c|c|}
\hline $\begin{array}{c}\text { Investigators } \\
\text { Parameters }\end{array}$ & $\begin{array}{c}\text { Present } \\
\text { stuy }\end{array}$ & $\begin{array}{c}\text { Lim } \\
(1997)\end{array}$ & $\begin{array}{c}\text { Husain el } \\
\text { al. (1998) }\end{array}$ & $\begin{array}{c}\text { Dey and } \\
\text { Barbhuiya } \\
(2005)\end{array}$ & $\begin{array}{c}\text { Nasrollahi } \\
\text { et al. } \\
(2008)\end{array}$ & $\begin{array}{c}\text { Coleman } \\
\text { et al. } \\
(2003)\end{array}$ \\
\hline$l(\mathrm{~m})$ & $0.06-0.2$ & $0.05-.15$ & $0.4-0.8$ & $0.06-.12$ & 0.25 & $0.05-4.75$ \\
\hline $\mathrm{V}(\mathrm{m} / \mathrm{s})$ & $0.159-0.21$ & $0.24-0.325$ & 0.1991 & $0.219-0.67$ & 0.3125 & $0.21-0.43$ \\
\hline $\mathrm{y}(\mathrm{m})$ & 0.1 & $0.1-0.15$ & 0.22 & $0.58-0.2$ & 0.128 & $0.05-.53$ \\
\hline $\mathrm{d} 50(\mathrm{~mm})$ & 0.27 & 0.94 & 0.775 & $0.26-1.86$ & 1.3 & $0.8-1.02$ \\
\hline $\mathrm{B}(\mathrm{m})$ & 1 & 0.6 & 1.37 & 0.9 & 2 & - \\
\hline
\end{tabular}

Table 2 Range of $\mathrm{V} / \mathrm{V}_{\mathrm{c}}$

\begin{tabular}{|c|c|}
\hline Discharge $(\mathrm{Q})$ & $\mathrm{V} / \mathrm{V}_{\mathrm{c}}$ \\
\hline $\mathrm{Q}_{1}$ & 0.63 \\
\hline $\mathrm{Q}_{2}$ & 0.75 \\
\hline $\mathrm{Q}_{3}$ & 0.84 \\
\hline
\end{tabular}

Table 3 Scour depth data at equilibrium stage

\begin{tabular}{|c|c|c|c|}
\hline Exp. Run & $l(\mathrm{~m})$ & Discharge $\left(\mathrm{m}^{3} / \mathrm{s}\right)$ & $\mathrm{d}_{\mathrm{s}}(\mathrm{cm})$ \\
\hline R1 & 0.06 & 0.0159 & 4.7 \\
\hline R2 & 0.06 & 0.0189 & 6.3 \\
\hline R3 & 0.06 & 0.0210 & 8.1 \\
\hline R4 & 0.085 & 0.0159 & 5.4 \\
\hline R5 & 0.085 & 0.0189 & 6.7 \\
\hline R6 & 0.085 & 0.0210 & 9.3 \\
\hline R7 & 0.1 & 0.0159 & 5.9 \\
\hline R8 & 0.1 & 0.0189 & 7.1 \\
\hline R9 & 0.1 & 0.0210 & 9.9 \\
\hline R10 & 0.12 & 0.0159 & 6.3 \\
\hline R11 & 0.12 & 0.0189 & 8.1 \\
\hline R12 & 0.12 & 0.0210 & 10.7 \\
\hline R13 & 0.2 & 0.0159 & 7.7 \\
\hline R14 & 0.2 & 0.0189 & 9.2 \\
\hline R15 & 0.2 & 0.0210 & 13.8 \\
\hline
\end{tabular}

Table 4 Scour Depth Data at Equilibrium Stage

\begin{tabular}{|l|c|c|c|c|c|}
\hline \multicolumn{1}{|c|}{ Researchers } & CC & MAE & MSE & MRSE & MAPE \\
\hline Present Study & 0.920 & 0.027 & 0.002 & 0.043 & 0.075 \\
\hline Dey and Barbhuyia (2005) & 0.854 & 0.038 & 0.012 & 0.091 & 0.188 \\
\hline Nagy (2004) & 0.836 & 0.042 & 0.173 & 0.053 & 0.250 \\
\hline Husain et al. (1998) & 0.430 & 0.121 & 1.591 & 1.261 & 0.789 \\
\hline Lim (1994) & 0.162 & 0.116 & 0.033 & 0.182 & 0.448 \\
\hline Frochlich (1989) & 0.805 & 0.037 & 0.082 & 0.286 & 0.241 \\
\hline
\end{tabular}




\section{Figure Captions}

Fig.1. Vortex system near an abutment or vertical wall spur dike (Kwan, 1984).

Fig. 2. Photometric view of experimental setup.

Fig. 3 (a). Comparison between computed and observed dimensionless scour depths using Frochlich (1989) with observed values.

Fig. 3 (b). Comparison between computed and observed dimensionless scour depths using Lim (1994) with observed values.

Fig. 3 (c). Comparison between computed and observed dimensionless scour depths using Husain et al. (1998) with observed values.

Fig.3 (d). Comparison between computed and observed dimensionless scour depths using Nagy (2004) with observed values.

Fig. 3 (e). Comparison between computed and observed dimensionless scour depths using Dey and Barbhuiya (2005) between observed and computed scour depth.

Fig. 4. Comparison between computed and observed dimensionless scour depths using present equation with observed values.

Fig. 5. Comparison between equation of Dey and Barbhuiya (2005) and present equation.

Fig. 6. Scour depth contours and scour hole at equilibrium stage.

Fig. 7 (a). Comparison between computed and observed dimensionless scour length upstream the spur dike.

Fig.7 (b). Comparison between computed and observed dimensionless scour length downstream the spur dike. 


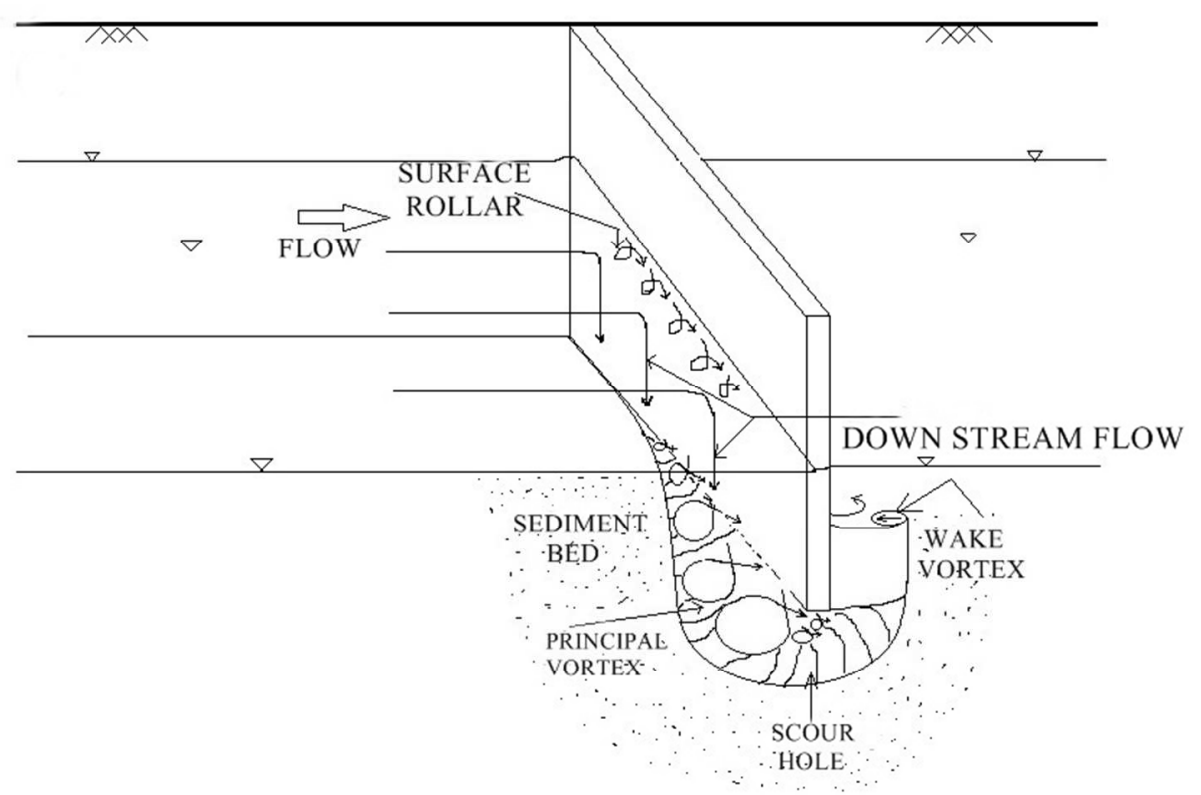

Fig.1. Vortex system near an abutment or vertical wall spur dike (Kwan, 1984).

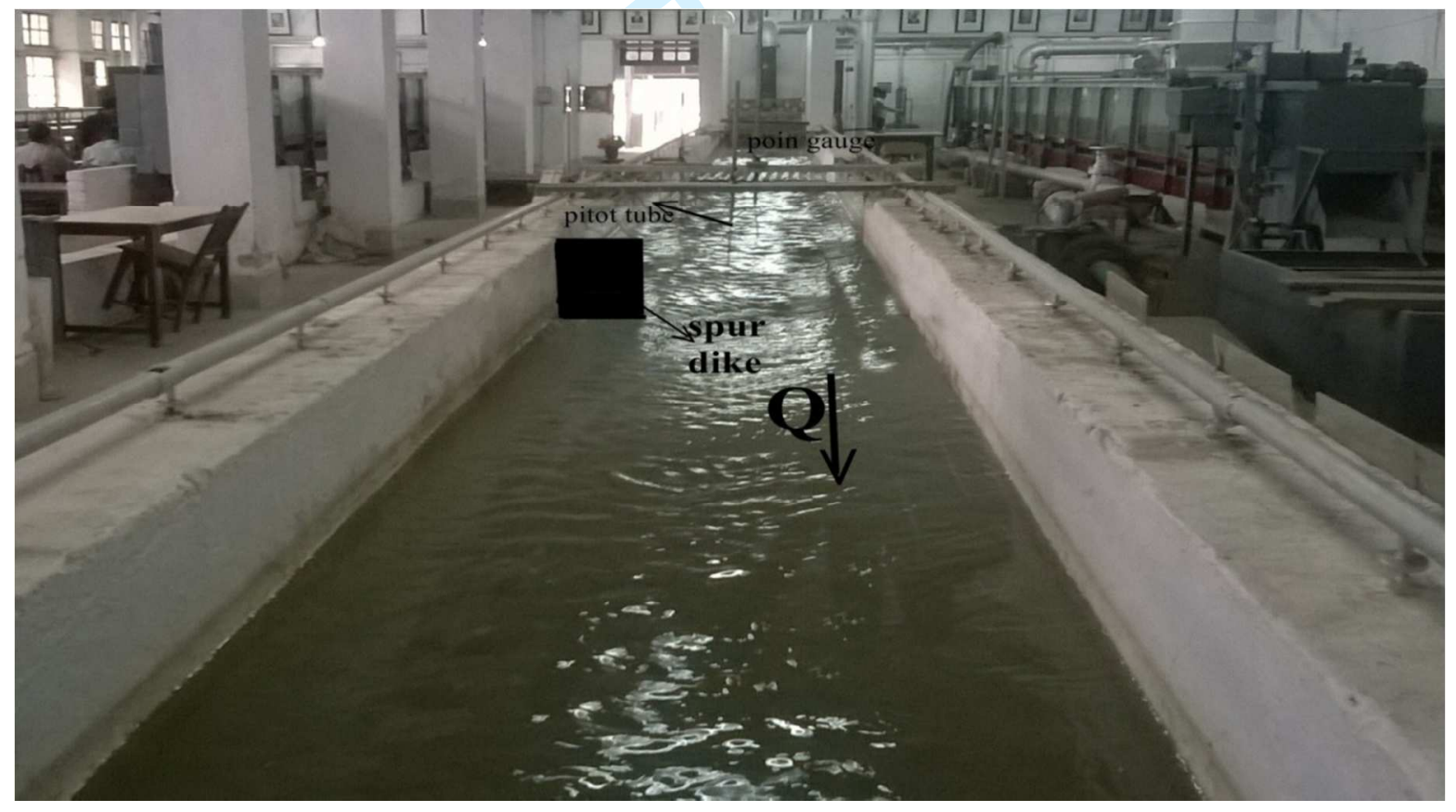

Fig. 2. Photometric view of experimental setup. 


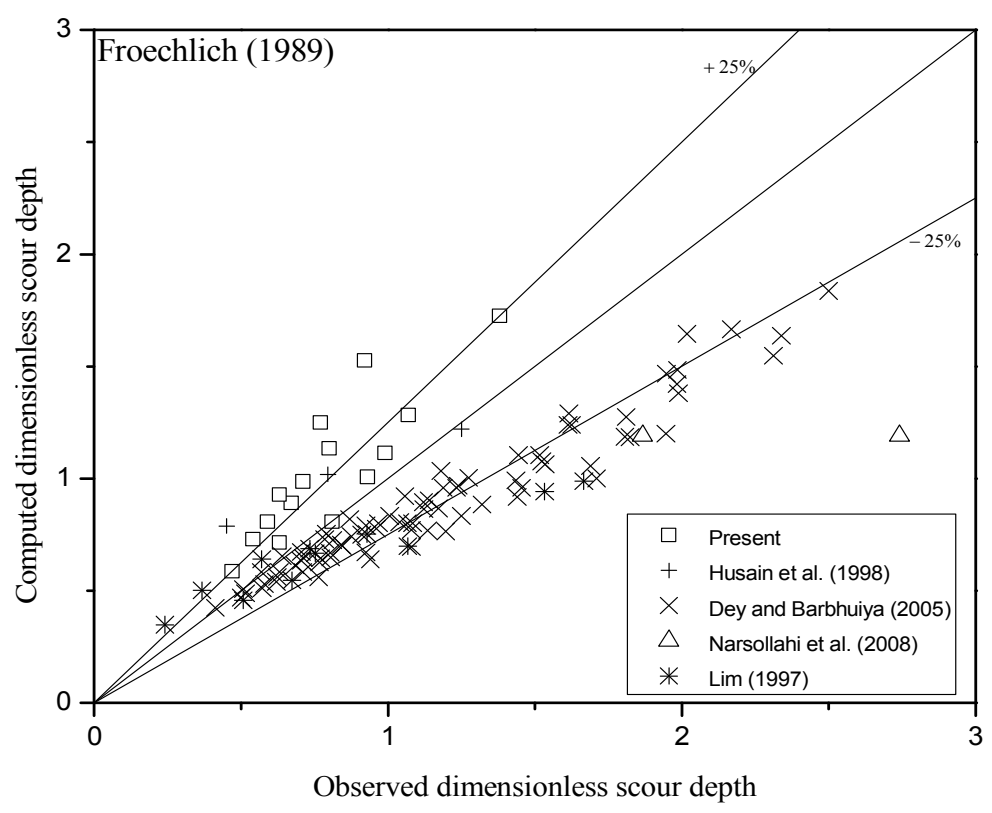

Fig. 3 (a). Comparison between computed and observed dimensionless scour depths using Frochlich (1989) with observed values.

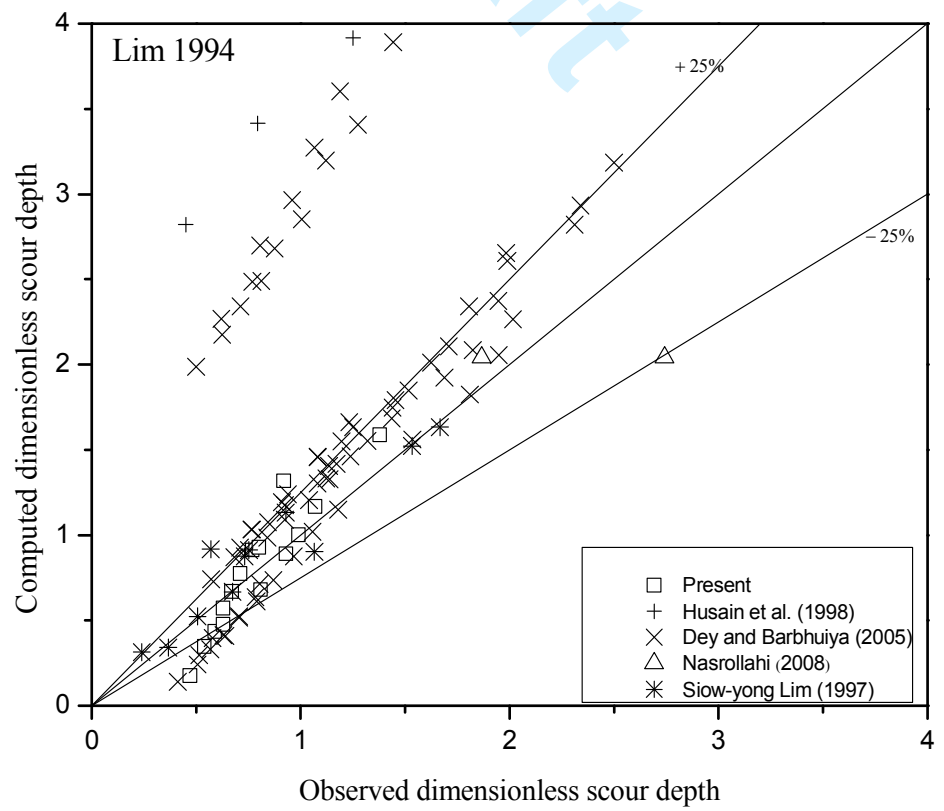

Fig. 3 (b). Comparison between computed and observed dimensionless scour depths using Lim (1994) with observed values. 


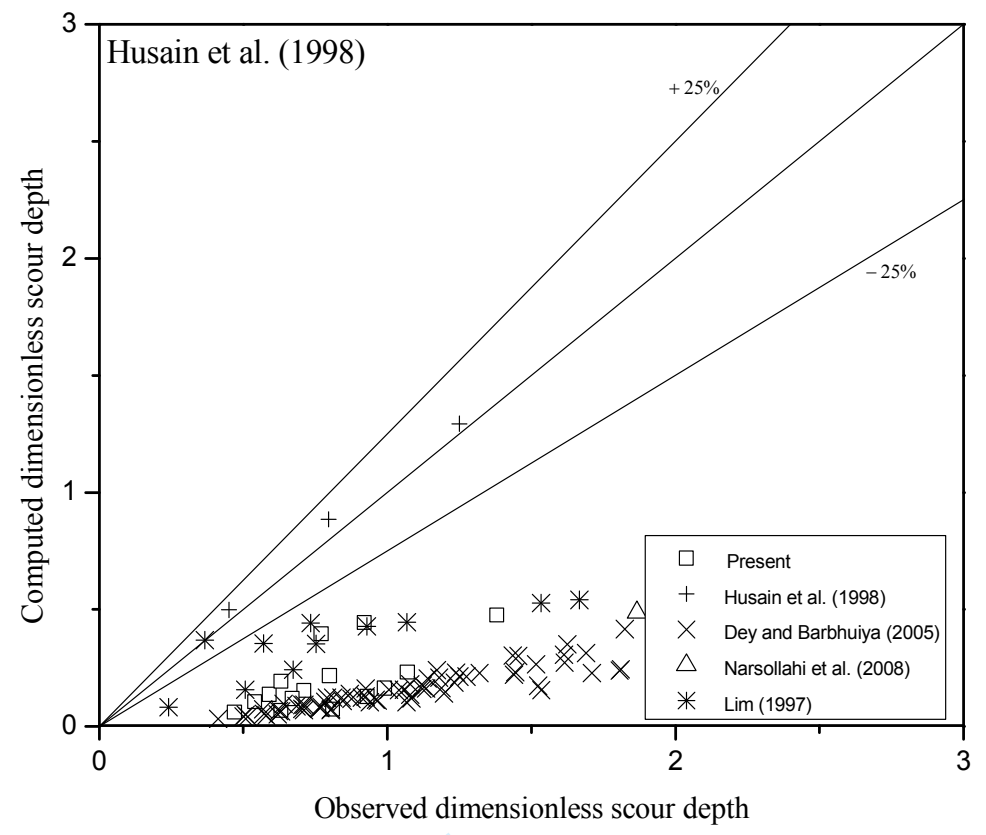

Fig. 3 (c). Comparison between computed and observed dimensionless scour depths using Husain et al. (1998) with observed values.

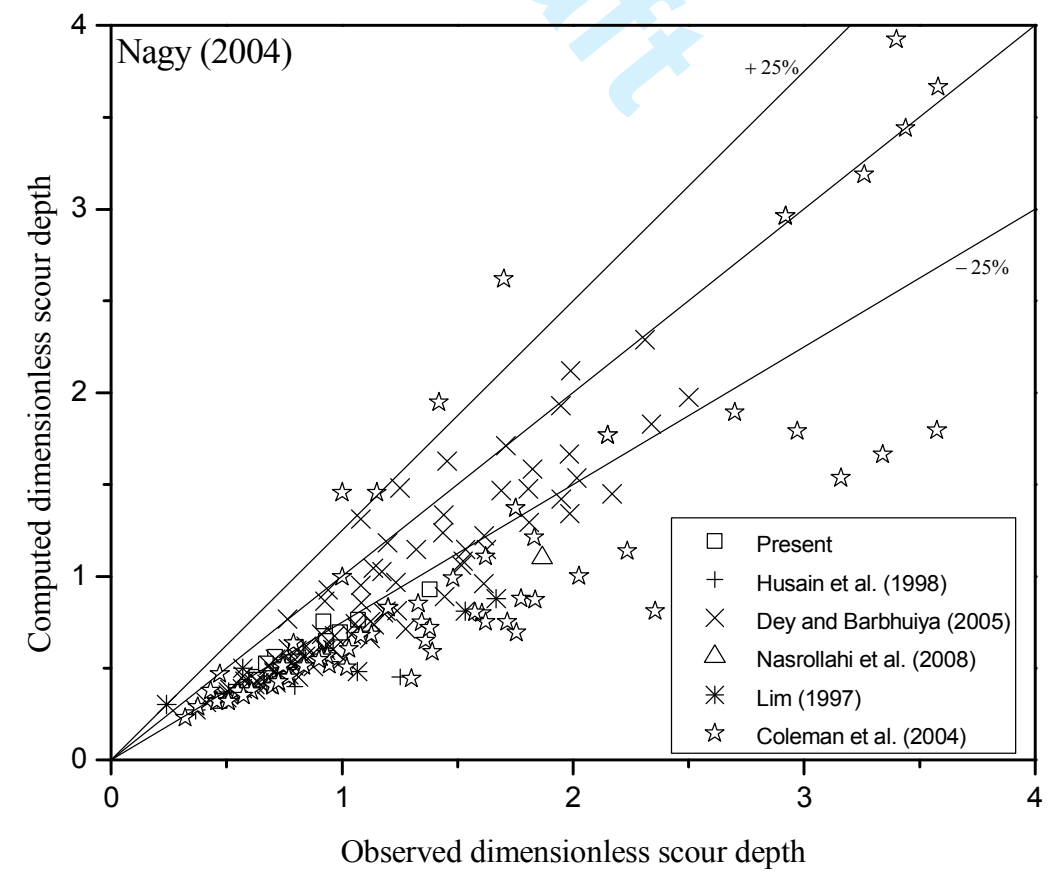

Fig.3 (d). Comparison between computed and observed dimensionless scour depths using Nagy (2004) with observed values. 


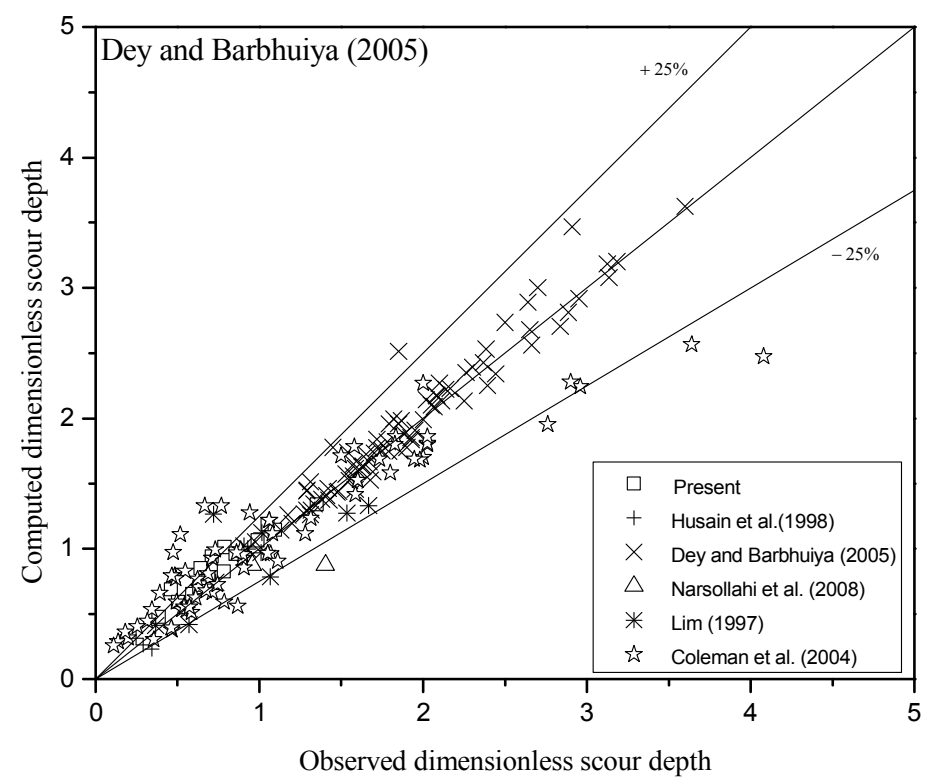

Fig. 3 (e). Comparison between computed and observed dimensionless scour depths using Dey and Barbhuiya (2005) between observed and computed scour depth.

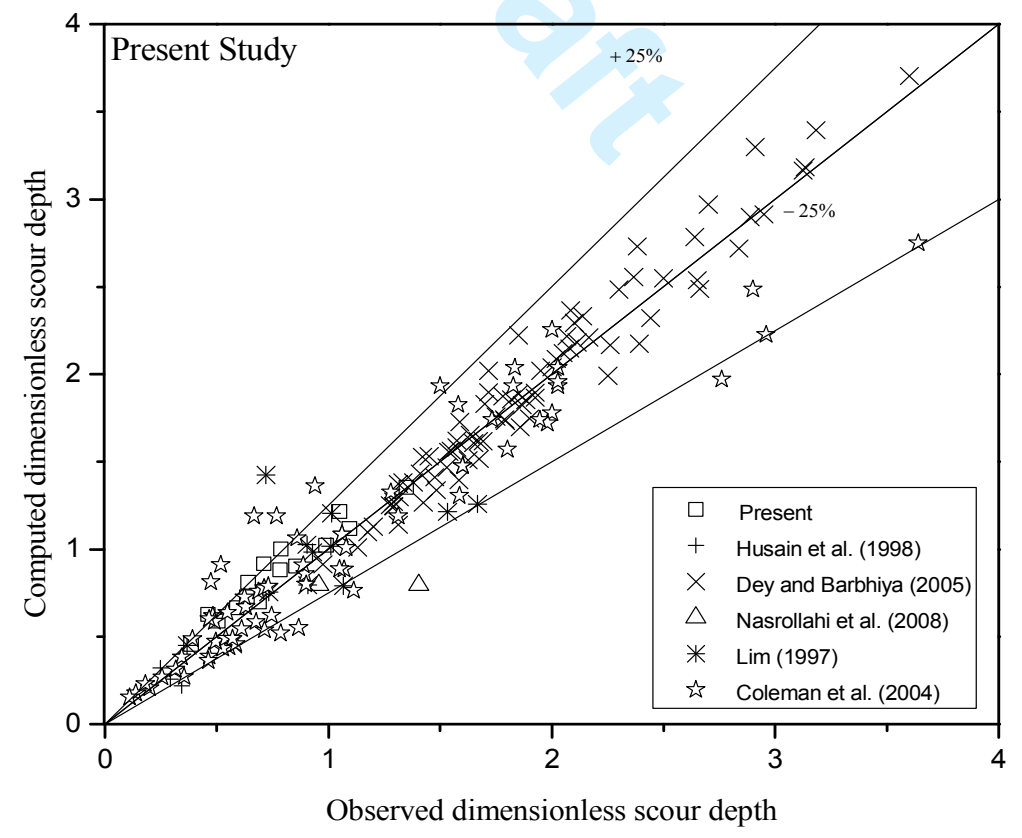

Fig. 4. Comparison between computed and observed dimensionless scour depths using present equation with observed values. 


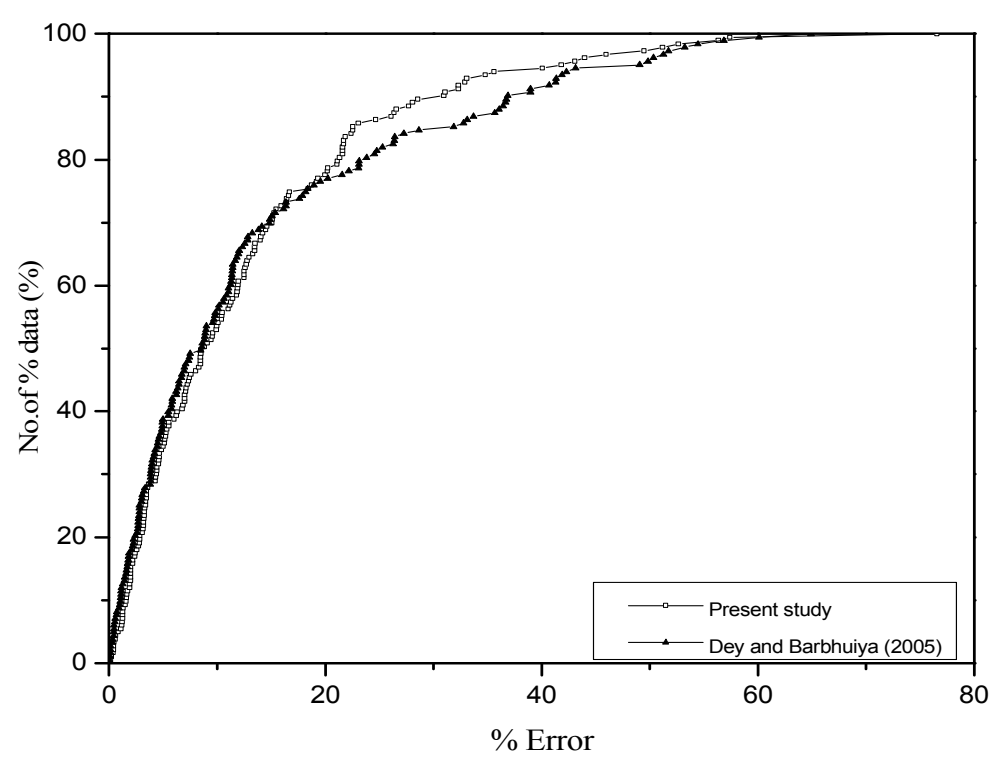

Fig. 5. Comparison between equation of Dey and Barbhuiya (2005) and present equation.
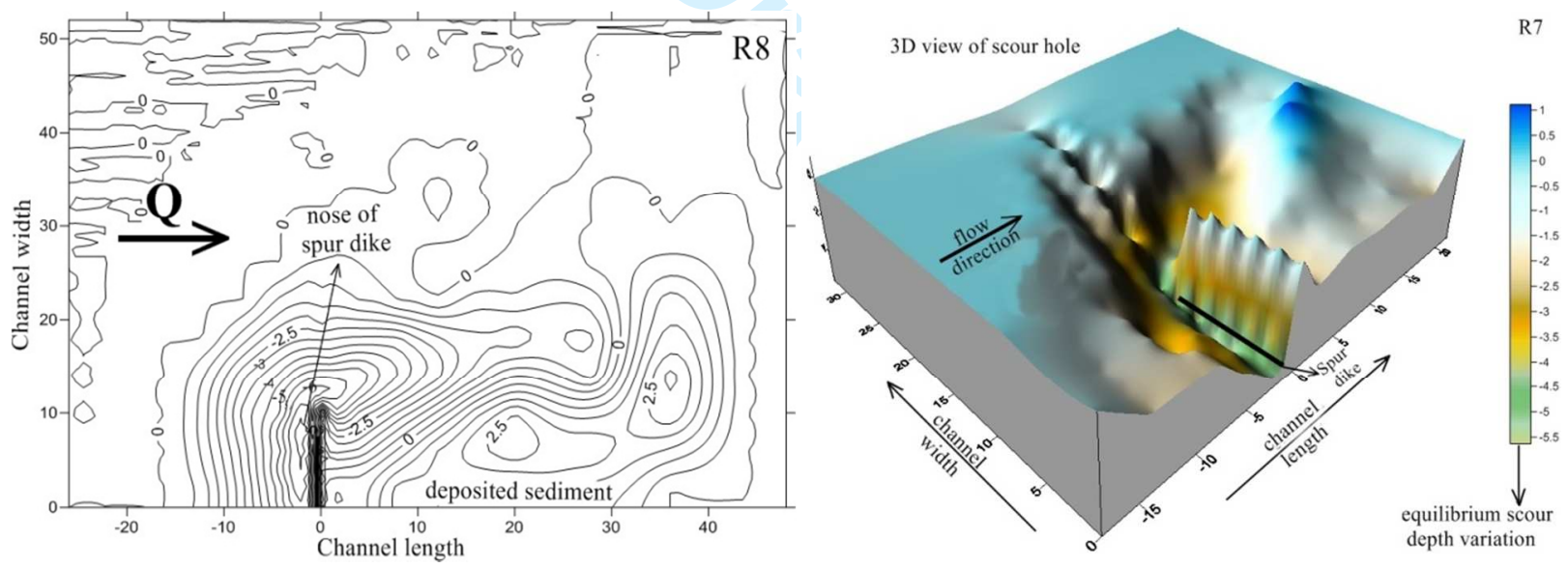

Fig. 6. Scour depth contours and scour hole at equilibrium stage. 


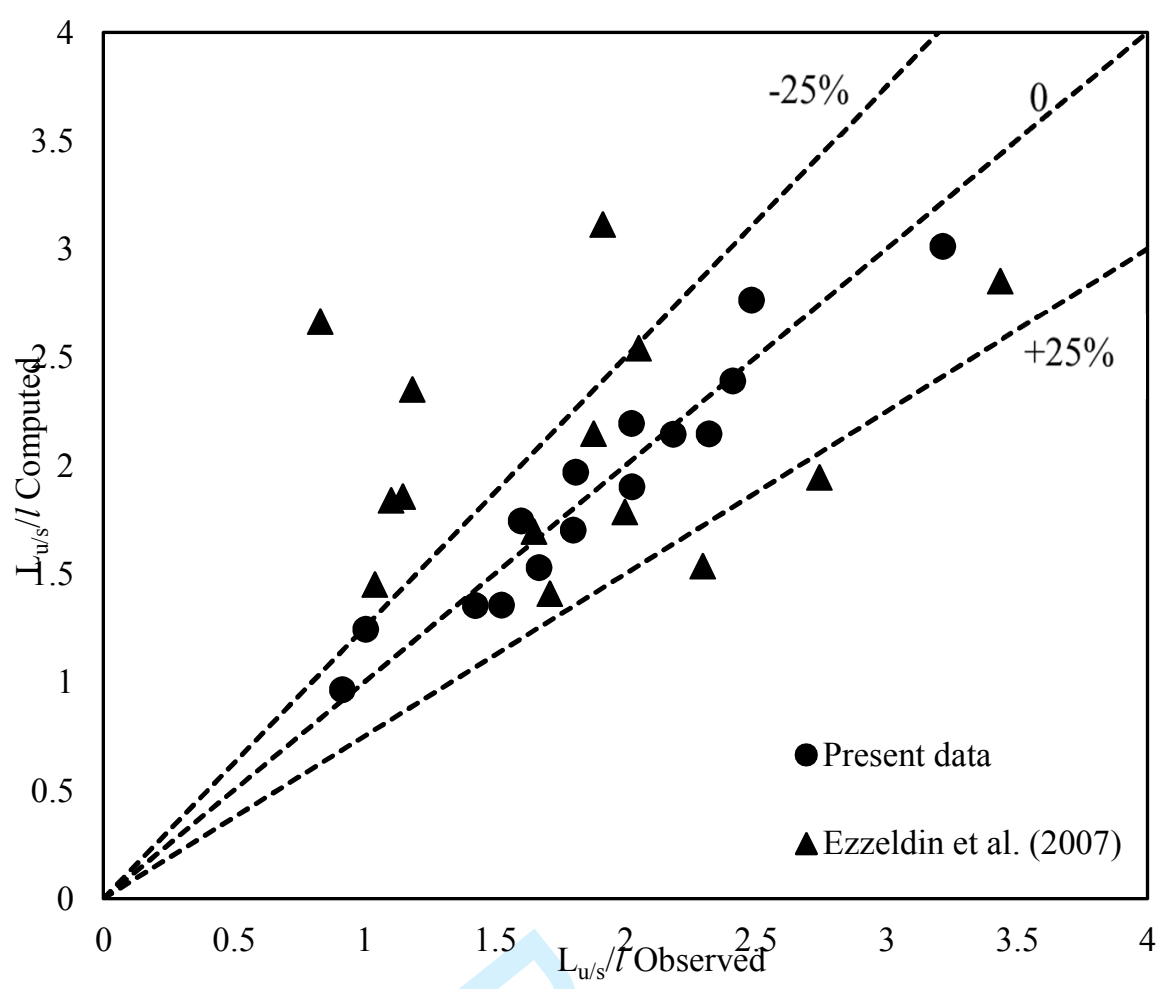

Fig. 7 (a). Comparison between computed and observed dimensionless scour length upstream the spur dike.

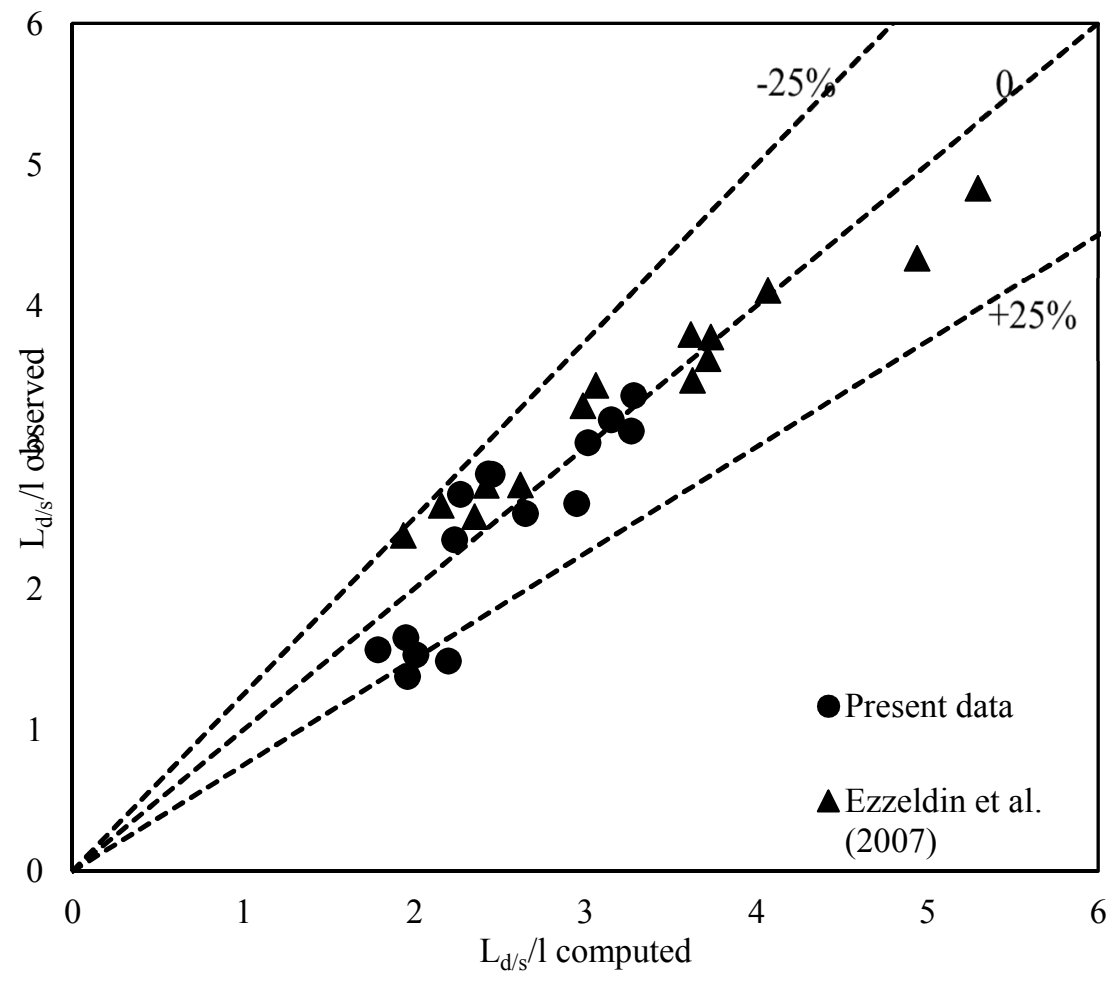

Fig.7 (b). Comparison between computed and observed dimensionless scour length downstream the spur dike. 